\title{
LIGHT MICROSCOPIC ANALYSIS OF CONTACTS BETWEEN PAIRS OF IDENTIFIED LEECH NEURONS WITH COMBINED USE OF HORSERADISH PEROXIDASE AND LUCIFER YELLOW ${ }^{1}$
}

\author{
SUSAN A. DERIEMER ${ }^{2}$ AND EDUARDO R. MACAGNO
}

Department of Biological Sciences, Columbia University, New York, New York 10027

\begin{abstract}
Intracellular injections of horseradish peroxidase (HRP) and Lucifer Yellow (LY) were used to determine the locations of possible synaptic contacts between pairs of identified leech neurons. The pairs studied were ipsilateral touch sensory neurons ( $\mathrm{T}$ cells), $\mathrm{T}$ cells plus the large longitudinal motoneuron ( $\mathrm{L}$ cell), and $\mathrm{T}$ cells plus the annulus erector motoneuron ( $\mathrm{AE}$ cell). The joint use of epi-fluorescence and transmitted light permitted the simultaneous observation of the processes of the HRP - and LY-filled cells. Our results indicate that, within the resolution of the light microscope, (a) over $40 \%$ of the varicosities of a $\mathrm{T}$ cell are in contact with those of another ipsilateral $\mathrm{T}$ cell, (b) both ipsilateral and contralateral $\mathrm{T}$ cells make numerous contacts with the two motoneurons studied, and (c) $\mathrm{T}$ cell-motoneuron contacts are distributed widely within the region where the cells overlap in the neuropil and occur on both major and minor processes of the motoneurons.
\end{abstract}

Synaptic connections between pairs of identified neurons have been the subject of numerous and thorough physiological and pharmacological studies in many species. In contrast, few attempts have been made to characterize such connections anatomically in corresponding detail, largely because of the complexity of the neuropil in which these connections are made. Functional contacts between a pair of neurons may be made at few or at many sites, in particular regions of the cells or at locations distributed throughout their surfaces, and on processes of different size, shape, or category (primary, secondary, etc.). Detailed knowledge of the number, location, and distribution of functional contacts on a neuron is essential for the analysis of its integrative functions (Scheibel and Scheibel, 1970). In addition, knowledge of these anatomical parameters may yield critical insights into the requirements placed upon the developmental mechanisms that give rise to specific connections in the central nervous system.

Complete anatomical mapping of synaptic contacts

\footnotetext{
' This work was initiated at the Marine Biological Laboratory in Woods Hole, MA, as a research project in the Neural Systems and Behavior Summer Course. We gratefully acknowledge the support of the Marine Biological Laboratory. We also thank Walter Stewart for a gift of Lucifer Yellow, William Kristan, Robert Schehr, and Thomas Consi for critical readings of the manuscript, and Linda Sproviero for typing it. This work was supported in part by United States Public Health Service Grant NS-14946 and a National Science Foundation predoctoral fellowship to S. A. D.

${ }^{2}$ Present address: Department of Pharmacology, Yale University Medical School, New Haven, CT 06510.

${ }^{3}$ To whom reprint requests should be addressed.
}

between pairs of identified neurons can best be achieved by means of reconstructions from serial electron micrographs. Practical difficulties, however, have limited the application of this approach to small neuronal networks, such as the visual system of Daphnia (Macagno et al., 1973; Macagno, 1977), the nervous system of Caenorhabditis elegans (Ward et al., 1975; Ware et al., 1975; White et al., 1976), and the stomatogastric ganglion of the lobster (King, 1976). A technique which is more readily applicable to larger systems, including the mammalian brain and particularly brain slices, is the injection of opaque or fluorescent dyes into the pair of cells under study. This approach allows the visual identification of the branches of the two cells within a complex neuropil in either cleared, whole-mounted tissue or in sections. Sites of close apposition between the cells then can be determined at the level of resolution of the light microscope, provided each dye-filled structure can be uniquely assigned to a neuron. This can be accomplished, for example, by means of computer reconstruction techniques if the same dye is used in both neurons (Macagno, 1978; Macagno et al., 1979), by using two dyes with different optical properties as described below, or by using an opaque dye in one neuron and a radioactively labeled tracer in the other along with autoradiography (Thompson et al., 1976). Although techniques that use the light microscope are limited to identifying the location of presumptive or possible synaptic sites, they can establish an upper limit to the number of such sites and define conclusively regions in which such sites do not exist. In addition, they allow one to make detailed comparisons of the three-dimensional branching patterns of 
complex identified cells which would be difficult, if not prohibitively time consuming, with electron microscopy alone. If the dyes are electron opaque, the tissue can be thin-sectioned subsequent to analysis with the light microscope and the nature of the contacts can be ascertained with the electron microscope.

In the leech Hirudo medicinalis, each midbody segmental ganglion contains about 400 neurons (Macagno, 1980). These include six mechanosensory cells which respond to light touch ( $\mathrm{T}$ cells; Nicholls and Baylor, 1968). T cells have a stereotypic number, shape, and distribution of processes within the neuropil and the simplest branching pattern of the leech sensory neurons studied thus far with intracellular dyes (Muller and McMahan, 1976). Electrophysiological studies have shown that $\mathrm{T}$ cells make rectifying electrical synaptic connections with several classes of identified cells, including other touch cells in their own and adjacent ganglia, sensory cells of other modalities, cells which innervate large areas of the body musculature, such as the annulus erector (AE) and large longitudinal (L) motoneurons, and at least one interneuron (reviewed in Muller, 1979). Chemical synapses between $T$ cells and unidentified neurons have been described anatomically (Muller and McMahan, 1976).

We have made use of the different optical properties of two intracellular markers, Lucifer Yellow (LY) and horseradish peroxidase (HRP) (Macagno et al., 1981), to examine the distribution of presumptive synaptic contacts between pairs of ipsilateral $\mathrm{T}$ cells and between $\mathrm{L}$ or AE motoneurons and both contralateral and ipsilateral $T$ cells in the same ganglion. Some of these observations have been reported previously in abstract form (DeRiemer and Macagno, 1980).

\section{Materials and Methods}

Segmental ganglia were dissected out singly or in pairs and pinned in Sylgard-coated plastic dishes containing standard leech Ringer's solution (Nicholls and Baylor, 1968). Sensory neurons and motoneurons were identified by the size and location of their cell bodies and, during intracellular recording, by their characteristic firing patterns and impulse size and shape (Nicholls and Baylor, 1968; Stuart, 1970). In some cases, the body wall was dissected along with the ganglion in order to confirm the identification of a motoneuron by its effect in the periphery. Final confirmation of cell identity was made by comparing the branching patterns of cells with those published by Muller and McMahan (1976).

The electrodes for horseradish peroxidase injection were filled with a solution consisting of $20 \mathrm{mg} / \mathrm{ml}$ of HRP (Sigma type VI) and $2 \mathrm{mg} / \mathrm{ml}$ of Fast Green in $0.2 \mathrm{M} \mathrm{KCl}$ and bevelled to resistances of 30 to 60 megohms. The solution was injected by applying short pressure pulses of 5 to 15 psi to the back of the electrode until a prominent coloration of the cell body was achieved. After allowing the HRP to diffuse within the cell's processes for 1 to $2 \mathrm{hr}$, a second and sometimes a third cell in the same ganglion were filled iontophoretically with Lucifer Yellow (3\% in $0.1 \mathrm{~m} \mathrm{LiCl}$; Stewart, 1978) using 500-msec hyperpolarizing pulses ( 5 to $10 \mathrm{nA}$ ) at a frequency of 1 $\mathrm{Hz}$ for $15 \mathrm{~min}$.

In order to preserve the LY fluorescence, we modified the standard procedure for HRP (Muller and McMahan, 1976) in the following manner (Macagno et al., 1981). After standing an additional $15 \mathrm{~min}$ in leech Ringer's solution, the ganglion was incubated, in the recording dish, in a solution of $0.5 \mathrm{mg} / \mathrm{ml}$ of diaminobenzidine tetrahydrochloride in Ringer's solution. After $5 \mathrm{~min}$, a few drops of $3 \%$ hydrogen peroxide were added to the solution and the incubation was allowed to proceed for another 2 to $5 \mathrm{~min}$. The HRP reaction was monitored under a dissecting microscope and stopped, when nonspecific reaction product began to appear in other cells, with several washes of Ringer's solution. Following a 1hr fixation with $4 \%$ paraformaldehyde in $0.1 \mathrm{M}$ phosphate buffer, $\mathrm{pH} 7.4$, ganglia were dehydrated in graded ethanol washes, then cleared and mounted in methyl salicylate.

The dye-filled cells were examined using either Leitz or Zeiss fluorescence microscopes and the number of secondary branches and varicosities of $T$ cells was determined. To facilitate the recording of the location of close appositions between processes, the HRP-filled cell was drawn first on a computer-coupled microscope (Macagno et al., 1979) or photographed. The HRP- and LY-filled cells then were examined simultaneously by balancing the intensity of the fluorescent epi-illumination and the transmitted light source until both the opaque and fluorescent cells were clearly visible. This was best achieved by placing a blue or deep green filter in front of the transmitted light source. Using a $\times 100$ oil objective, the locations of close appositions (called "contacts" herein) between the processes of the two cells were recorded on the computer drawing or photograph of the HRP-filled neuron. Under these conditions, the resolution in the image plane is better than $0.5 \mu \mathrm{m}$; the depth resolution is difficult to measure and is probably no better than 1 to $2 \mu \mathrm{m}$.

A possible difficulty in this procedure could arise from the fact that Lucifer Yellow is known to cross some electrical synapses in the leech (see Muller, 1979). However, although ' $\mathrm{I}$ ' cells (the only cells filled with LY in this study) make such junctions with other $\mathrm{T}$ cells and cells of other types, we found no evidence that the dye diffuses from a $\mathrm{T}$ cell to other cells. In particular, we saw no morphological differences between $T$ cells filled with HRP and T cells filled with LY, suggesting not only that LY stays within T cells but also that the HRP diffuses throughout the $\mathrm{T}$ cell branching field in the ganglion.

\section{Results}

$T$ cell pairs. Four pairs of ipsilateral $\mathrm{T}$ cells were studied in three segmental ganglia from a single leech. A ganglion in which two pairs were dye-filled is shown in Figure $1 a$. In all cases, the filled cells were those that innervate the ventral and lateral regions of the skin (Nicholls and Baylor, 1968).

The branching patterns of ventral and lateral $T$ cells were found to be very similar and not distinguishable from one another (cf., Muller, 1979, p. 109). This can be seen readily in Figure $1 b$. Secondary branches (by convention, all of those that branch off of the main processes; see Fig. $1 a$ ) of one cell frequently resembled those of the other cell and appeared to follow adjacent paths and terminate in the same areas in the neuropil. The number of secondary branches (see Table I) varied from cell to 

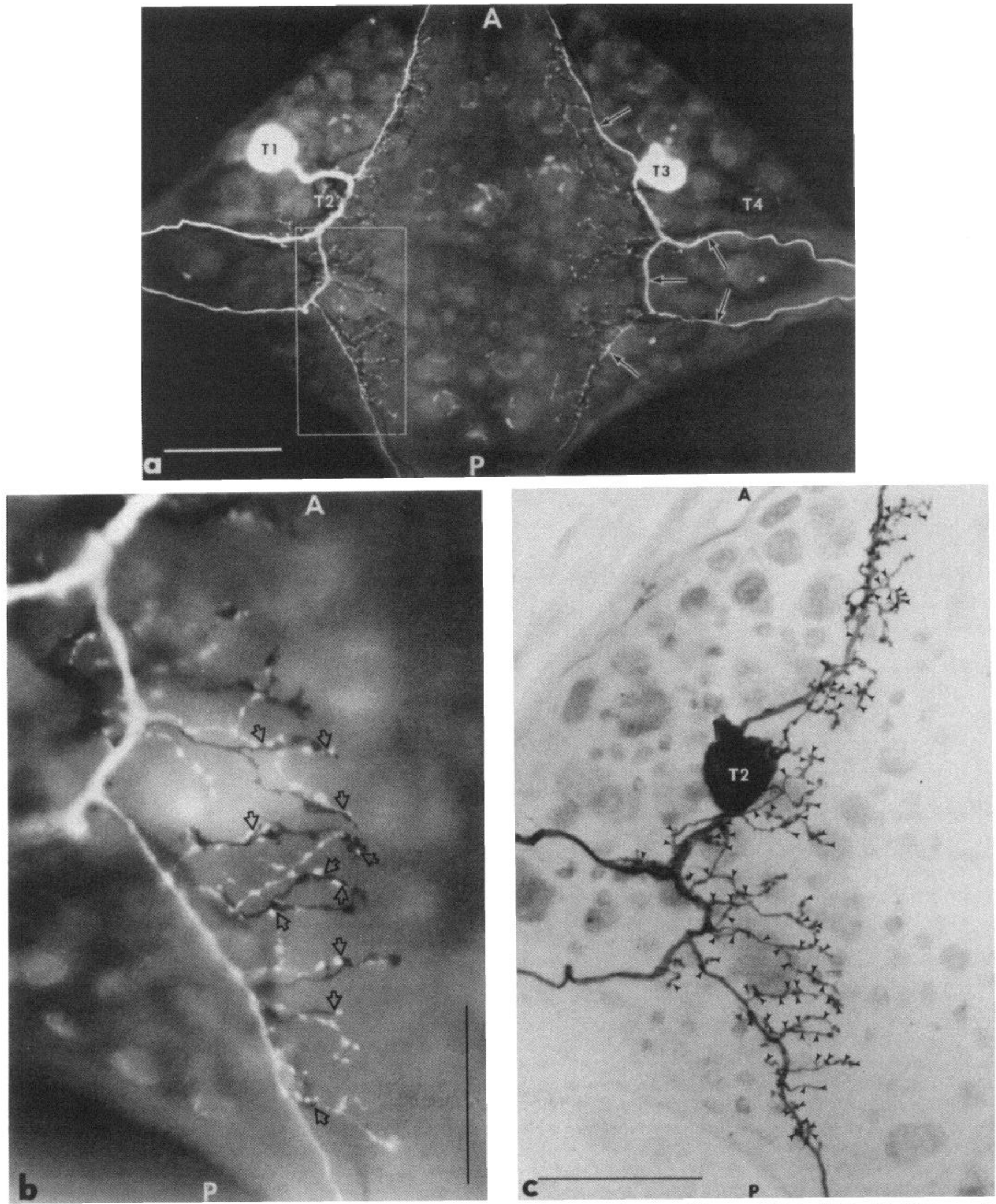

Figure 1. Two pairs of dye-filled ventral and lateral T cells in ganglion 8. Cells T1 and T3 were filled with Lucifer Yellow; cells $\mathrm{T} 2$ and T4 were filled with horseradish peroxidase. In this figure and those that follow: $A$, anterior; $P$, posterior. $a$, Low power micrograph showing a dorsal view of the ganglion. Scale bar, $100 \mu \mathrm{m}$. Each T cell has main processes (indicated by arrows on T3) and numerous secondary branches with varicosities which come off of the main processes and extend into the neuropil. The box at the lower left indicates the area shown at higher magnification in $b$. $b$, Detail of $a$ photographed at higher magnification and with less depth of field. Scale bar, $50 \mu \mathrm{m}$. Examples of varicosities forming contacts between T1 and T2 and marked by arrows. $\approx$, Micrograph of the HRP-filled T cell on the left of ganglion 8 (cell T2), with the location of all observed contacts indicated by arrowheads. Numerical data for this and other T cells are given in Table I. Scale bar, $100 \mu \mathrm{m}$. 
cell. The six cells studied in ganglia 7 and 8 had an average of $42 \pm 5$, whereas the two cells in ganglion 19 had only $20 \pm 5$.

A similar difference was found in the number of varicosities (see Table I), which have been shown by Muller and McMahan (1976) to be the locations of chemical synaptic sites (both pre- and postsynaptic) in these cells. The six cells in ganglia 7 and 8 had an average of 237 \pm 21 varicosities; the two in ganglion 19 each had only 178 and 180 . However, the average number of varicosities per secondary branch was greater in ganglion 19 (9 per branch) than in ganglia 7 and 8 (5 to 6 per branch).

Contacts between $T$ cell pairs almost always were found to be at the sites of varicosities of the two cells on secondary or tertiary branches (see Fig. 1b). A few contacts were found between a varicosity of one cell and a main process of the other (though, at our level of reso-

TABLE I

Properties of $T$ cell pairs in three segmental ganglia of one leech

$\mathrm{T} 1$ and $\mathrm{T} 2$ are lateral or ventral touch cells on the left side of the ganglion; T3 and T4 are those on the right side.

\begin{tabular}{|c|c|c|c|c|c|}
\hline Ganglion & Cell & Dye & $\begin{array}{l}\text { Secondary } \\
\text { Branches }\end{array}$ & Varicosities & Contacts \\
\hline \multirow[t]{2}{*}{8} & $\mathrm{~T} 1$ & LY & 42 & 264 & \multirow{2}{*}{99} \\
\hline & $\mathrm{T} 2$ & HRP & 41 & 222 & \\
\hline \multirow[t]{2}{*}{8} & $\mathrm{~T} 3$ & LY & 37 & 227 & \multirow{2}{*}{96} \\
\hline & $\mathrm{T} 4$ & HRP & 51 & 252 & \\
\hline \multirow[t]{2}{*}{7} & T3 & LY & 36 & 216 & \multirow{2}{*}{99} \\
\hline & T4 & HRP & 43 & 255 & \\
\hline \multirow[t]{2}{*}{19} & T1 & LY & 16 & 178 & \multirow{2}{*}{92} \\
\hline & $\mathrm{T} 2$ & HRP & 25 & 180 & \\
\hline
\end{tabular}

lution, a very short secondary branch would be hard to distinguish from a sharp bend in a main process). Unlike the differences among ganglia discussed above, we found that the number of contacts between $T$ cell pairs was about the same in all cases studied (see Table I) with an average of $96 \pm 3$ contacts per pair. Approximately $40 \%$ of the varicosities of one $\mathrm{T}$ cell in ganglion 19 were closely apposed to those of the other, and in ganglia 7 and 8, the percentage was $54 \%$. Furthermore, as is evident in Figures $1 c$ and 2 , these contacts were distributed throughout the $\mathrm{T}$ cell branching field.

$T$ cell-motoneuron pairs. Both ipsilateral and contralateral $\mathrm{T}$ cell contacts with the $\mathrm{L}$ and $\mathrm{AE}$ motoneurons were examined. A ganglion with an HRP-filled L motoneuron and two LY-filled T cells is shown in Figure $3 a$, with a magnification for detail in Figure $3 b$. The locations of contacts between $\mathrm{T}$ cells and an $\mathrm{L}$ cell are indicated on the $\mathrm{L}$ cell shown in Figure 4. Examples of T cell-AE motoneuron double fills are shown in Figure 5.

In the three contralateral T-L pairs studied, the numbers of contacts were 24,29 , and 31 ; in the two ipsilateral T-L pairs, the numbers of contacts were 13 and 24. As can be seen in Figures $3 b$ and 4 , contacts were distributed widely. Contacts always occurred at or adjacent to a $\mathrm{T}$ cell varicosity. As shown in Figure $3 b$, they were found directly on the motoneuron's main processes (or on very short spines on these processes; arrow 1 in Fig. $3 b$ ) as well as on higher order branches near and far from the main processes (arrows 2 to 5 in Fig. $3 b$ ), generally on the slender spines which are typical of this cell type (Muller and McMahan, 1976).

In the four contralateral T-AE pairs examined, the number of contacts varied from 22 to 41 (mean $32 \pm 9$ ); in four ipsilateral T-AE pairs, the number varied from 2
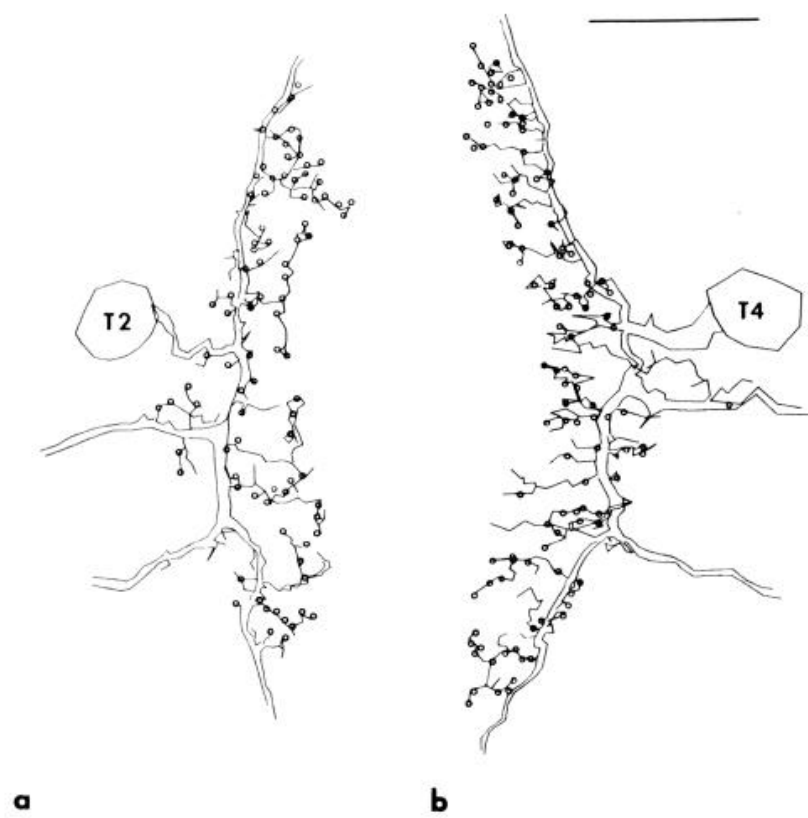

c

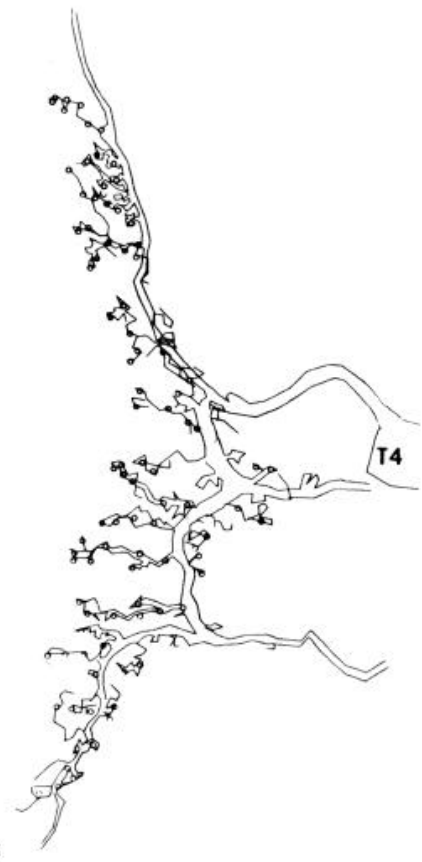

Figure 2. Location of contacts between T cells in three different ganglia. In each case, the HRP-filled T cell (T2 or T4) has been drawn with the aid of a computer and the sites of contacts with the LY-filled cell (not shown) are indicated by open circles. The numerical data are presented in Table I. $a$, Cells on the left side of ganglion $19 ; b$, cells on the right side of ganglion $7 ; c$, cells on the right side of ganglion 8 , visible in the micrograph in Figure 1a. Anterior, top; posterior, bottom. Scale bar in $b, 100 \mu \mathrm{m}$. 

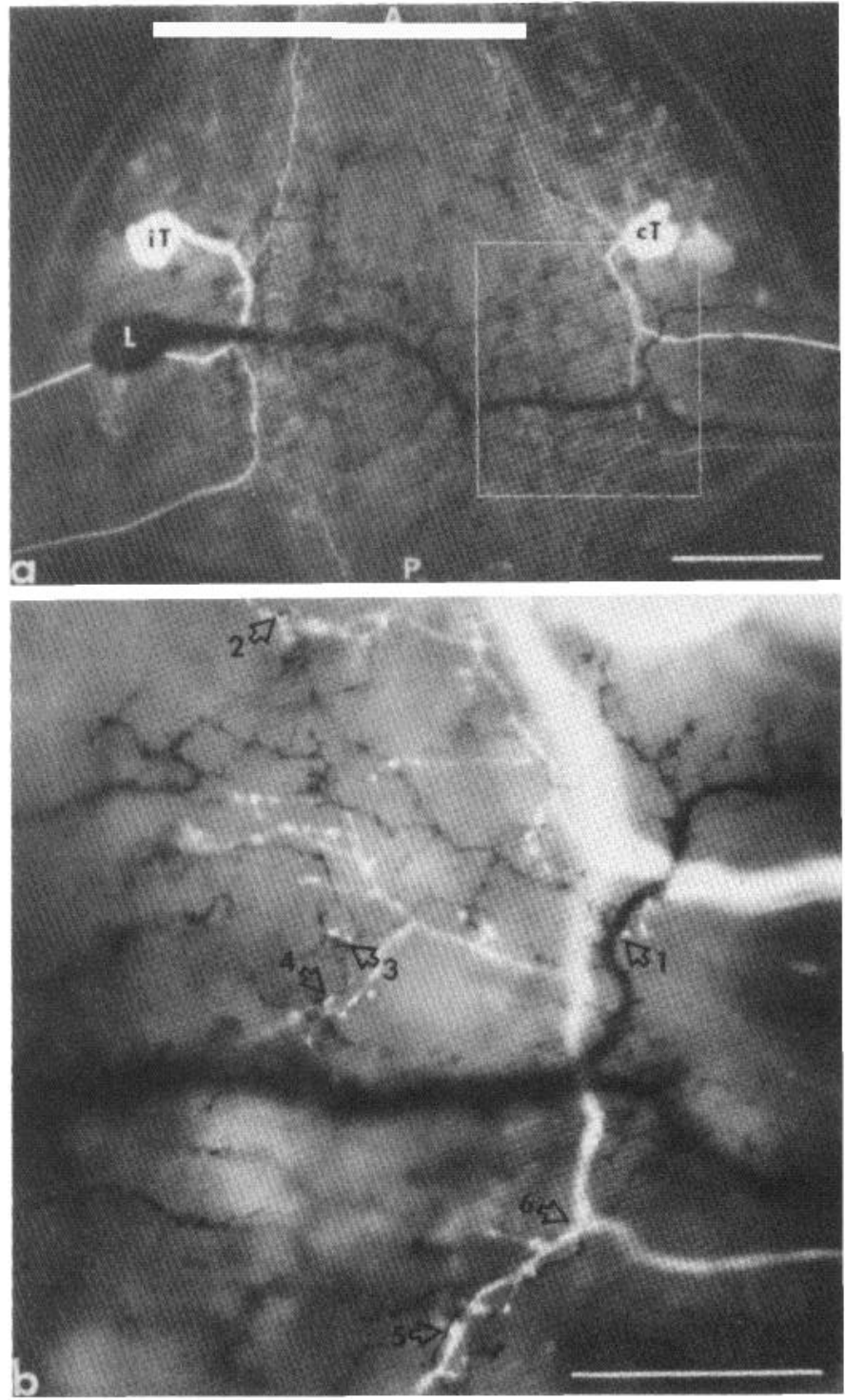

Figure 3. a, Micrograph of an HRP-filled L motoneuron $(L)$ and LY-filled ipsilateral $(i T)$ and contralateral $(c T)$ touch sensory neurons. The box indicates the area of the detail shown in $b$. Scale bar, $100 \mu \mathrm{m}$. $b$, Detail of $a$ showing examples of contacts in anterior (arrow 2), central (arrows 1, 3, and 4), and posterior (arrow 5) regions of neuropil. These are found both on primary (arrow 1) and secondary (arrows 2 to 5 ) branches of the L cell. Arrow 6 indicates a branch point where a conduction block would probably occur as suggested by Yau (1976). Scale bar, $50 \mu \mathrm{m}$.

to 14 (mean $7^{\circ} \pm 5$ ). As in the case of the $\mathrm{L}$ motoneuron, contacts were distributed widely. However, since the main processes of the AE travel almost exclusively contralaterally to their cell body (see Fig. 5), contacts with the ipsilateral $\mathrm{T}$ were found only on the fine, higher order branches of the AE which are located in the posterior region of the ipsilateral neuropil.

\section{Discussion}

The distribution of observed contacts between pairs of neurons. Our observations show that ipsilateral T cells overlap extensively within the lateral regions of neuropil

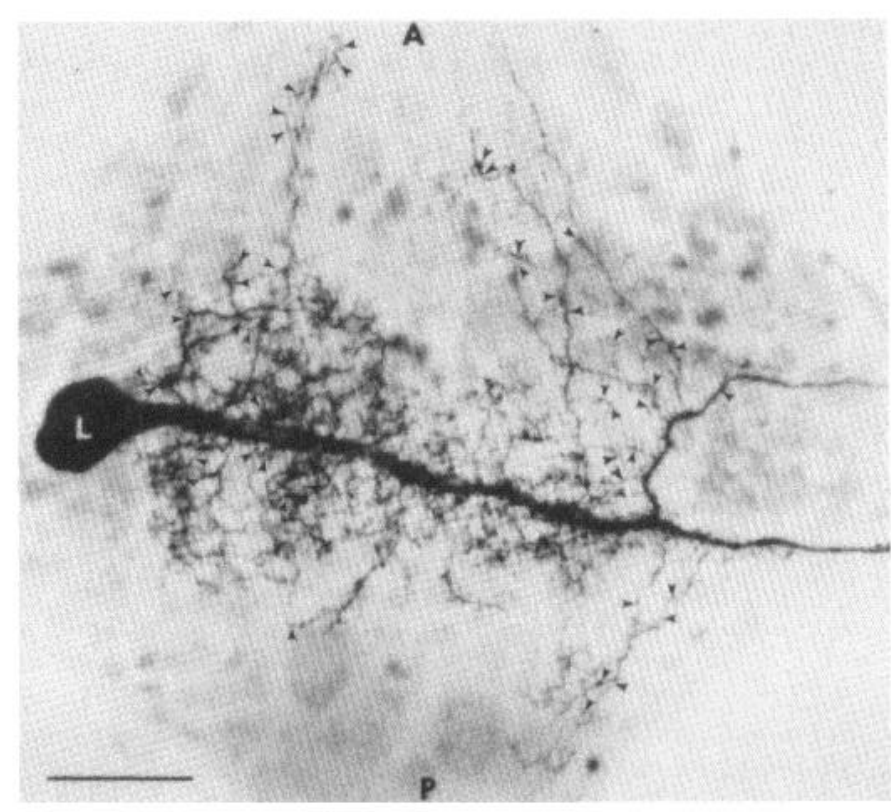

Figure 4. Location of contacts (indicated by arrowheads) between an HRP-filled L motoneuron $(L)$ and both an ipsilateral (contacts to the left of the $A-P$ line) and a contralateral (contacts to the right) T cells. Neither LY-filled T cell is visible in this transmitted light micrograph. Scale bar, $100 \mu \mathrm{m}$.

defined by their dendritic fields. Furthermore, the numerous contacts that we found between their varicosities are distributed widely in the region of overlap with no apparent segregation of contacts to any particular area within this region. Contralateral pairs of $\mathrm{T}$ cells do not overlap at all and, hence, make no direct contacts with one another, a fact reported previously by other workers (see Muller, 1979).

Our data also show that the bilateral dendritic fields of $\mathrm{L}$ and $\mathrm{AE}$ motoneurons overlap with the fields of T cells on both sides of the ganglion. The overlap of $\mathrm{L}$ cells with both contralateral and ipsilateral $\mathrm{T}$ cells extends over a large part of the regions occupied by the T cells. This is also the case for $\mathrm{AE}$ and contralateral $\mathrm{T}$ cells but not for $\mathrm{AE}$ and ipsilateral T cells. Since the ipsilateral half of the dendritic field of the $\mathrm{AE}$ cells is restricted to a posterior region of the neuropil, the overlap in this case extends only over the posterior region of the $\mathrm{T}$ cell field. The observed contacts between $T$ cell varicosities and processes of the two motoneurons are distributed widely and are not restricted to either a specific area of the overlap region or to motoneuron processes of a particular size or category. The location of contacts within these regions varies somewhat among the homologous pairs studied, reflecting the intrinsic variability of the fine features of the branching patterns of these neurons. Whether contacts are distributed in a completely random manner over the region of overlap remains to be ascertained from the examination of a larger number of cases.

These observations raise several basic questions about the distribution of intercellular contacts. For example:

1. Do other pairs of neurons (in the leech or other species) distribute their contacts uniformly over the regions where their dendritic fields overlap? 

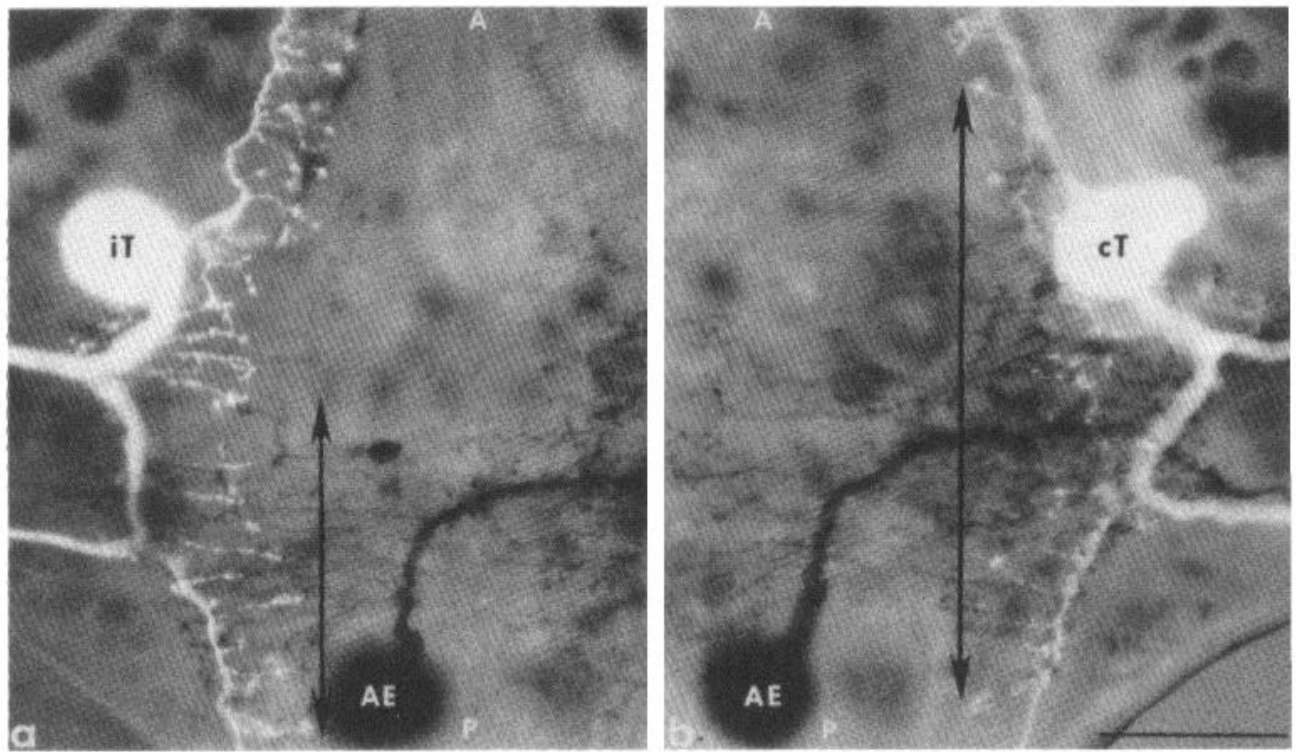

Figure 5. Low power micrographs of HRP-filled AE motoneurons $(A E)$ and LY-filled T cells. $a$, Ipsilateral T cell $(i T)$ and $A E ; b$, contralateral T cell $(c T)$ and $A E$. The region where $i T$ and $A E$ overlap is smaller and more posterior than the region where $c T$ and $A E$ overlap (regions delimited by arrows in $a$ and $b$ ). The letters $A$ and $P$, representing anterior and posterior, respectively, are located approximately at the midplane of the ganglion. Scale bar, $100 \mu \mathrm{m}$.

2. Could $\mathrm{T}$ cells form contacts onto other regions of the motoneurons' dendritic fields if the regions of overlap were experimentally shifted?

3. Is the number of contacts between two cells proportional to the number of processes that they send into the region of overlap?

Answers to these questions, which will be obtained by the further application of the techniques that we have described here, are of fundamental importance to our understanding of the anatomical basis for the observed physiological interactions among these cells.

Functional implications. To the extent that physiological measurements indicate that direct synaptic connections exist between these pairs of cells, we can expect that at least some of the contacts that we observed must be synaptic. Whether all are cannot be determined from our observations because of the limited resolution of the light microscope. There are many processes in the leech neuropil with diameters of $0.2 \mu \mathrm{m}$ or less which could lie between the closely apposed marked processes and be invisible to us. Rigorous anatomical proof would require that every site of close apposition be examined in the electron microscope. Since the enormous amount of work that this would entail makes it unlikely that such direct proof will be forthcoming, it is useful to consider alternative, less direct approaches to test this possibility. In the discussion that follows, we consider our observations in light of the published physiological evidence for synaptic interactions among these cells and suggest some physiological experiments to test whether the close appositions observed at different locations are indeed synaptic contacts.

Baylor and Nicholls (1969) have shown that all T cells in a ganglion are interconnected through electrical and chemical synapses: An action potential in one $\mathrm{T}$ cell produces a short latency, electrical postsynaptic potential and several delayed chemical EPSPs and IPSPs in the five other $T$ cells. The characteristics of these postsynaptic responses led them to propose that $\mathrm{T}$ cells make direct, double rectifying electrical synapses on one another (positive but not negative current passes in either direction between these cells) but that the chemical connections are polysynaptic. It is clear from our data that there are many sites of close apposition at which the direct electrical interactions between ipsilateral $\mathrm{T}$ cells might occur. If this is the case, the wide distribution of these contacts would suggest that any region of a $\mathrm{T}$ cell can sense the activity of other ipsilateral cells. Since processes of $\mathrm{T}$ cells are separated widely in the neuropil from those of their contralateral homologues (Nicholls and Purves, 1970; Muller and McMahan, 1976; Muller, 1979; see also Fig. 1), the electrical connections between contralateral pairs of $\mathrm{T}$ cells must be polysynaptic rather than direct. An interneuron which mediates this interaction has been described recently by Muller and Scott (1979).

While it is likely that the contacts at or near varicosities are the sites of coupling between ipsilateral T cells, ultrastructural evidence for electrical synapses has been difficult to obtain in the leech and Muller and McMahan (1976) described only chemical synapses at varicosities. It is possible, therefore, that the coupling between ipsilateral $\mathrm{T}$ cells is mediated by another neuron and that the close appositions that we observed are sites where both $\mathrm{T}$ cells make adjacent chemical synapses onto a common target. That the interneuron coupling contralateral $\mathrm{T}$ cells does not mediate the electrical interaction between ipsilateral $\mathrm{T}$ cells was demonstrated by Muller and Scott (1981). They showed that destroying this neu- 
ron with intracellular injection of a protease did not affect the capacity of ipsilateral T cells to depolarize each other electrically.

The observation of contacts between $T$ cells and the $L$ motoneuron supports the suggestion, derived from physiological measurements (Nicholls and Purves, 1970, 1972), that these cells are coupled directly through rectifying electrical synapses. Variable numbers of contacts were observed between the $\mathrm{L}$ and both contralateral and ipsilateral T cells. The observed variability in the number of contacts, and hence potentially of synaptic sites, is not unusual; variable numbers of synaptic sites between identified neurons have been reported previously, for example, in Daphnia (Macagno et al., 1973). The functional consequences of these variations, however, remain unexplored. A somewhat larger number of contacts was found, on the average, between $\mathrm{L}$ and contralateral $\mathrm{T}$ cells. Since, in addition, the spike initiation zone of the $\mathrm{L}$ cell is probably located distally from the cell body (Stuart, 1970) in the region where its processes exit from the ganglion through the contralateral roots (see Fig. 4), we might expect that the contralateral $\mathrm{T}$ cells are more capable of evoking an impulse in the $\mathrm{L}$ cell than the ipsilateral $\mathrm{T}$ cells.

An additional prediction about the functional consequences of the distribution of T-L contacts follows from the observation that these contacts are made on the $L$ cell by secondary branches from all of the major processes of a $\mathrm{T}$ cell. Conduction block, whereby prior activity can prevent impulses from invading certain regions of the cell's branching field, has been shown to occur in $\mathrm{T}$ cells under conditions of stimulation consistent with those occurring in the intact animal (Van Essen, 1973; Ya11, 1976). It has been proposed as a means by which these cells and others can modulate their output in a usedependent manner and provides a means for testing physiologically for the existence of synaptic connections in particular areas of a cell's dendritic field (Muller and Scott, 1981). The widespread distribution of contacts described here indicates, for example, that impulses generated at the posterior minor sensory field and blocked at the posterior branch point of the main $\mathrm{T}$ cell processes (Yau, 1976; see also Fig. $3 b$ ) would not eliminate signaling between a touch cell and the contralateral L since such an impulse could still activate many of the synaptic sites available (e.g., arrow 5 in Fig. $3 b$ ). Reduction of the effectiveness of the electrical synaptic connections between a $\mathrm{T}$ cell and an interneuron due to branch point failure has been described recently by Muller and Scott (1981), but changes in the T-L coupling under these circumstances have yet to be explored physiologically.

Our observations of T-AE cell pairs, which also are reported to be electrically connected (Muller and $\mathrm{Ni}$ cholls, 1974), show that there are numerous contacts where direct electrical synapses could exist. The lateral asymmetry in the number of contacts is more pronounced here than in T-L pairs: There are, on the average, 32 contacts between AE and contralateral $\mathrm{T}$ cells and only 7 between AE and ipsilateral T cells. The same argument about the location of the spike initiation zone applies to the AE motoneuron (Stuart, 1970) so that we arrive at a similar conclusion about the effectiveness of T-AE coupling: We expect contralateral T-AE coupling to be more effective in firing the AE cell than ipsilateral T-AE. The contacts between the latter pair, however, are not distributed throughout all regions of the ipsilateral $\mathrm{T}$ but only on posterior branches (see Fig. $5 a$ ). Hence, we would predict that a conduction block at the posterior branch point of the $\mathrm{T}$ cell would have much less effect on the size of the electrical postsynaptic potential in the AE motoneuron than in the $\mathrm{L}$ motoneuron, a hypothesis that can be tested physiologically.

\section{References}

Baylor, D. A., and J. G. Nicholls (1969) Chemical and electrical synaptic connections between cutaneous mechanoreceptor neurons in the central nervous system of the leech. J. Physiol. (Lond.) 203: 591-609.

DeRiemer, S. A., and E. R. Macagno (1980) Positional correlation of synaptic boutons in pairs of mechanosensory cells in the leech. Biol. Bull. 159: 483.

King, D. G. (1976) Organization of crustacean neuropil. II. Distribution of synaptic contacts on identified motoneurons in lobster stomato-gastric ganglion. J. Neurocytol. 5: 239-266.

Macagno, E. R. (1977) Abnormal synaptic connectivity following UV-induced cell death during Daphnia development. In Cell and Tissue Interactions, J. W. Lash and M. M. Burger, eds., pp. 293-309, Raven Press, New York.

Macagno, E. R. (1978) Mapping synaptic sites between identified neurons in the leech CNS by means of 3-D computer reconstructions from serial sections. Brain Theory Newsletter 3: $186-189$.

Macagno, E. R. (1980) Number and distribution of neurons in leech segmental ganglia. J. Comp. Neurol. 190: 283-302.

Macagno, E. R., V. Lo Presti, and C. Levinthal (1973) Structure and development of neuronal connections in isogenic organisms: Variation and similarities in the optic system of Daphnia magna. Proc. Natl. Acad. Sci. U. S. A. 70: 57-61.

Macagno, E. R., C. Levinthal, and I. Sobel (1979) Three-dimensional computer reconstruction of neurons and neuronal assemblies. Annu. Rev. Biophys. Bioeng. 8: 323-351.

Macagno, E. R., K. J. Muller, W. B. Kristan, S. A. DeRiemer, R. Stewart, and B. Granzow (1981) Mapping of neuronal contacts with intracellular injection of horseradish peroxidase and Lucifer Yellow in combination. Brain Res. 221: in press.

Muller, K. J. (1979) Synapses between neurons in the central nervous system of the leech. Biol. Rev. 54: 99-134.

Muller, K. J., and U. J. McMahan (1976) 'The shapes of sensory and motor neurons and the distribution of their synapses in ganglia of the leech: A study using intracellular injection of horseradish peroxidase. Proc. R. Soc. Lond. (Biol.) 194: 481499.

Muller, K. J., and J. G. Nicholls (1974) Different properties of symapses between a single sensory neuron and two different motor cells in the leech C.N.S. J. Physiol. (Lond.) 238: 357369.

Muller, K. J., and S. A. Scott (1979) Direct electrical synaptic connection is mediated by an interneuron. Soc. Neurosci. Abstr. 5: 744.

Muller, K. J., and S. A. Scott (1981) Transmission at a "direct" electrical connection mediated by an interneuron in the leech. J. Physiol. (Lond.) 311: 565-583.

Nicholls, J. G., and D. A. Baylor (1968) Specific modalities and receptive fields of sensory neurons in the CNS of the leech. J. Neurophysiol. 31: 740-756.

Nicholls, J. G., and D. Purves (1970) Monosynaptic chemical and electrical connections between sensory and motor cells 
in the central nervous system of the leech. J. Physiol. (Lond.) 209: 647-667.

Nicholls, J. H., and D. Purves (1972) A comparison of chemical and electrical synaptic transmission between single sensory cells and a motoneuron in the central nervous system of the leech. J. Physiol. (Lond.) 225: 637-656.

Scheibel, M. E., and A. B. Scheibel (1970) Of pattern and place in dendrites. Int. Rev. Neurobiol. 13: 1-26.

Stewart. W. W. (1978) Intracellular marking of neurons with a highly fluorescent naphthalimide dye. Cell 14: 741-759.

Stuart, A. E. (1970) Physiological and morphological properties of motoneurons in the central nervous system of the leech. J. Physiol. (Lond.) 209: 627-646.

Thompson, E. B., C. H. Bailey, V. F. Castellucci, and E. R. Kandel (1976) Two different and compatible intracellular labels: A preliminary structural study of identified sensory and motor neurons which mediate the gill withdrawal reflex in Aplysia californica. Soc. Neurosci. Abstr. 2: 337.
Van Essen, D. C. (1973) The contribution of membrane hyperpolarization to adaptation and conduction block in sensory neurons of the leech. J. Physiol. (Lond.) 230: 509-534.

Ward, S., N. Thompson, J. G. White, and S. Brenner (1975) Electron microscopical reconstruction of the anterior sensory anatomy of the nematode Caenorhabditis elegans. J. Comp. Neurol. 160: 313-338.

Ware, R. W., D. Clark, K. Crossland, and R. L. Russell (1975) The nerve ring of the nematode Caenorhabditis elegans: Sensory input and motor output. J. Comp. Neurol. 162: 71110.

White, J. G., E. Southgate, J. N. Thompson, and S. Brenner (1976) The structure of the ventral nerve cord of Caenorhabditis elegans. Philos. Trans. R. Soc. Lond. (Biol.) 275: 327348.

Yau, K. -W. (1976) Receptive fields, geometry and conduction block of sensory neurons in the CNS of the leech. J. Physiol. (Lond.) 263: 513-538. 